\title{
Territorios y oficios a su usanza. Qeros, aquillas y matis andinos coloniales (siglos XVI y XVII)
}

\section{Territories and traditional workshops. Qeros, aquillas and matis colonial andean $\left(16^{\text {Th }}\right.$ and $17^{\text {th }}$ centuries)}

María Carolina Odone C. ${ }^{1}$ https://orcid.org/0000-0001-9999-8955

${ }^{1}$ Instituto de Historia, Pontificia Universidad Católica de Chile. Av. Vicuña Mackenna 4860, Macul, Santiago de Chile, CHILE. Email: modoneco@uc.cl

\section{Resumen}

Este artículo propone indagaciones, en el ámbito del sur andino colonial, respecto de la presencia de qeros, aquillas y matis en distintos espacios geográficos y contextos de uso. Interesa preguntar por contextos de producción y circulación en territorios y colectivos sociales, pesquisando la presencia de carpinteros y plateros indígenas, a fin de reflexionar sobre las posibles continuidades de las prácticas de sus oficios a su usanza.

Palabras claves: qeros, aquillas, matis, contextos de producción y circulación, sur andino colonial.

\begin{abstract}
This article proposes lines of research in the colonial Southern Andes concerning the presence of qeros, aquillas and matis. It recognises distinct geographical areas and contexts of use; considers the contexts of production and circulation in the territories and social collectivities; investigates the presence of indigenous carpenters and silversmiths; and reflects on possible continuities of the practices of their traditional workshops.
\end{abstract}

Keywords: Qeros, aquillas, matis, contexts of production and circulation, colonial Southern Andes.

Recibido: 18 octubre 2016. Aceptado: 24 julio 2017 


\section{Presentación del problema}

Los qeros, aquillas y matis tienen una historicidad previa a la llegada de los conquistadores europeos a los Andes del Sur. Estos objetos estaban insertos en sistemas económicos, políticos y religiosos de Estados centrales y élites gobernantes. También estaban presentes en las comunidades aldeanas, en los ayllus y entre sus kuracas o señores naturales. Eran objetos que anclaban en el sistema de las obligaciones y reciprocidades con el mundo de los vivos, de los muertos, el culto a los ancestros, las wak'as y divinidades. Ellos estaban comprometidos y disponibles dentro del armazón simbólico y ritual de la densa malla de negociaciones que movía las vidas de las gentes indias.

En época precolombina, las aquillas de oro y plata tenían una fuerte carga simbólica y, al igual que los qeros, eran usadas, en contextos religiosos y políticos y en patrón de a pares, por las élites gobernantes. También eran bienes de poder y prestigio que los señores naturales recibían como regalos por servicios o prestaciones (Money, 2004). Las de oro tenían un mayor prestigio, utilizándose en ceremonias de carácter político-ritual, como alianzas y reconocimientos, en ceremoniales de coronación y/o duelo del Sapan Inka, y en las celebraciones del Inti Rai$m y$ (Ziółkowski, 1979; Zasada, 1985). Estos objetos sellaban relaciones entre el Sapan Inka y las élites cusqueñas, y entre ellas y los kuracas de todas las provincias del imperio. A partir de la conquista hispana "desaparecieron casi completamente las vasijas de oro, y las de plata se convirtieron en un lujo que solo se pudieron permitir algunos kurakas verdaderamente ricos" (Ziółkowski 1979, p. 21). Muchos de estos objetos fueron fundidos, otros, vendidos y su valor fue integrado a las cajas reales (Money, 2004).

Para el sur andino colonial, los qeros se han abordado en tanto sistemas de registro y comunicación con códigos, culturalmente establecidos, compuestos por categorías con significantes concretos. Estos objetos de indios no solo representaban acontecimientos, sino que también reflexiones y/o contenidos de la vida social prehispánica y de la colonialidad. Lo que permite pensarlos como medios comunicacionales portadores de significados y mensajes que narraban hechos de memorias de las gentilidades o antigüedades, pero también presentaban temáticas sobre el acontecer colonial y el modo en que las gentes indias comprendían el mundo y los tiempos que estaban viviendo (Martínez y Martínez, 2013; Martínez et al., 2014, 2016).

En relación a los territorios de producción y circulación de estos objetos, mucho se ha avanzado en la identificación de espacios de producción. Por una parte, Cusco y sus áreas vecinas; por otra, el ámbito del Omasuyo o borde oriental del lago Titikaka, en áreas como Escoma, Carabuco y Sampaya. Y el distrito urbano de la ciudad de La Plata o Chuquisaca (Flores, Kuon y Samanez, 1997; Gisbert, 1999; Cummins, 2004; Martínez et al., 2014 y 2016.) A su vez, esta geografía de espacios productivos ha permitido identificar estilos o tradiciones con temáticas visuales propias, como se observa en los qeros cusqueños, en los de estilo Omasuyos-lago Titikaka y en los qeros de estilo Charazani (Martínez et al., 2014, 2016.)

Sobre los matis coloniales, recientes investigaciones dan cuenta de que, en la década de 1560, en la ciudad de Arequipa circulaban mates de calabaza pequeños y grandes. Además había otro tipo de mates, también para beber, aunque identificados como mates pintados (Odone y Durán, 2017). La tradición de su elaboración, al menos prehispánicamente, no se corresponde con su pintura, pues estos, en general, eran pirograbados, por ende cabe la pregunta de si los matis pintados tendrían que ser pensados en tanto qeros.

El propósito del presente trabajo es presentar evidencias procedentes tanto de crónicas, relaciones y visitas como de documentos del Archivo Regional de Cusco (ARC), del Archivo Regional de Arequipa (ARA) y del Archivo La Paz (ALP), los que, en su conjunto, permiten identificar la presencia de qeros, aquillas y matis, desde una escala espacio-temporal amplia. Justamente desde esa mirada escalar este artículo se levanta a fin de preguntar por los contextos de producción y circulación que la presencia de estos objetos va dibujando.

Estas aproximaciones etnohistóricas son solo preliminares y provisionales, y su objetivo es dar cuenta 
de la diversidad y riqueza de qeros, aquillas y matis, testimoniada por la diversidad de fuentes primarias y secundarias revisadas. A su vez interesa aportar a una discusión mucho más amplia sobre cómo las gentes indias rearmaron su uso, en el contexto de la colonialidad hispana, y cómo la vida de esos objetos fue trazando huellas y circulaciones de memorias, usos y costumbres que apelaban no solo a experiencias sociales y culturales que se estaban viviendo, sino también al modo en que sus usuarios mantenían, en la transformación de sus vidas, sus sistemas de creencias y valores, sus mundos-visiones, sus categorías de pensamiento donde los ancestros, los parientes, las fiestas, los seres de otra dimensión y los presagios seguían moviendo el mundo, las personas, sus vidas y la de sus difuntos.

\section{Presencia de aquillas, qeros y matis en Cusco colonial}

En 1558 Polo Ondegardo, corregidor del Cusco (1558-1561), dictaba una ordenanza para regular la vida en las rancherías o arrabales de la ciudad, ya que allí habitaban "mas de veinte mil indios de diversas personas e otros, que viven libremente" (Esquivel y Navia, 1980 [1749], Tomo 1, p. 197). Este proceso de reducción de población indígena fue continuado por el virrey Conde de Nieva, posteriormente por el gobernador Lope García de Castro y, por último, el virrey Francisco de Toledo le dio forma final a las reducciones indígenas en torno a Cusco (Pease, 1992, p. 197).

Lo más preocupante no eran los indios de encomienda, sino los que 'vivían libremente' ya que sobre ellos no había ningún control. Por esta razón los indios y sus ayllus fueron agrupados en torno a parroquias de indios, no solo para que su evangelización fuese más efectiva, sino que también para vigilar, a través de autoridades indígenas, sus vidas, usos y costumbres (González, 1982, p. 178).

$\mathrm{Al}$ congregarse a poblaciones indígenas y sus ayllus en torno a parroquias, se fueron configurando barrios de especialización productiva. Alrededor de las parroquias de Belén y San Santiago se reunieron, entre otros, ayllus de alfareros (Martínez, D., 2015, p. 133). En las cercanías de la parroquia Hospital de
Naturales (o San Pedro), cuya construcción se inició en 1556, "se hallaron olleros, posiblemente de la costa" (Rowe, 1990, p. 371). En el barrio de San Blas se agrupó a "carpinteros, imagineros y retablistas" (Gutiérrez et al., 1981, p. 68). Alrededor de la parroquia de San Sebastián, lugar donde "existían finas canteras de arcilla” (Kuon-Arce, 2011, p. 130), se congregaron los olleros.

Los indios plateros estaban agrupados en torno a las parroquias de San Santiago y San Cristóbal, aunque también alrededor de Santa Ana y San Sebastián (Vetter, 2016a, p. 41). Particularmente interesante es la presencia de plateros en la parroquia de San Santiago dado que hacia allí fueron traslados plateros yungas del ayllu Herbay, Ysma o Ishma. Estos plateros, en tiempos de Huayna Capac, habían sido asentados como mitmaq en las cercanías de Cusco, en Picoypampa o Picoy, en las pampas de Anta y desde allí fueron relocalizados en Cusco (Espinoza, 1987, Tomo I, p. 62; Carcedo, Vetter y Diez, 2004, p. 155; Vetter, 2008, p. 117).

En época del Tawantinsuyu los orfebres fabricaban objetos destinados a la élite, como las aquillas o vasos ceremoniales, además de ornamentos corporales y cefálicos y otros objetos (Money, 2004; Vetter, 2016a y b). En época prehispánica "las aquillas podían fabricarse sin ninguna decoración o con una iconografía muy rica y variada" (Vetter, 2016b, p. 129). Las aquillas incas "solían lucir la decoración en el tercio superior del vaso. Esta se caracterizó por su iconografía geométrica", aunque también se han encontrado aquillas incaicas sin ninguna decoración (Vetter, 2016b, p. 129).

La información que se ha relevado permite documentar que los cocos de plata y/o aquillas seguían presentes y circulando entre las gentes indias. El término cocos de plata como sinónimo de aquilla surge a partir de información testamentaria de los bienes de Christóbal Cautín, principal del pueblo de Tuza, en el norte de Ecuador, quien tenía "dos cocos de plata que en lengua del Cuzco llama aquillas" (Cummins, 2002, p. 81).

En la visita realizada en 1572 al pueblo de Urcos, del Marquesado de Orepesa, situado en las cercanías del distrito urbano de Cusco, aún eran conservadas 
las aquillas entre los señores naturales. El kuraca principal de Urcos, Garcia Toma, junto a tierras, cosechas de maíz, papas, ganados de la tierra, ovejas de Castilla, un caballo y arboledas, declaraba poseer "unos cocos de plata" (La visita de Urcos de 1572, en Rostworowski, 2005 [1993], p. 322, f. 190r). Surge la pregunta de si esos 'cocos de plata' del $k u$ raca Garcia Toma pudieron ser regalados en el contexto de relaciones reciprocitarias entre el Inca y los señores locales, puesto que el valle de Yucay, donde se sitúa Urcos, perteneció "al Inca Huayna Capac, en calidad de propiedad privada" (Rostworowski, 2005 [1993], p. 319). Un caso similar de aquillas de plata en manos de señores naturales se observa en el testamento del kuraca del pueblo de Anta Francisco Orco Supa, quien en 1585 conservaba "unos dos cocos de plata que pessan/ diesiseis pesos". ${ }^{1}$ Otro aspecto interesante es el patrón relacionado con la posesión de aquillas en pares, al igual que los qeros.

También se detecta la presencia de aquillas en el contexto de unidades familiares, como se observa en el testamento de Anjelina Tanbo [sic] de 1586:

[...] yten declaro que tengo dos aquillas de plata que / ambos pares pesan doze [pesos] / [mando] los gozen mi [padre: sic] / y [madre: sic] y no se entienda los ayan por suyos mas de que / por todos los dias desu vida de los [dichos] mis padres / y después [mando] se den las unas a mi hijo [juan] sac/ sa [sic] mi hijo y las otras [tachado] a costansa tamta [tachado] mi hija. ${ }^{2}$

Es muy significativo observar cómo las aquillas, por el mecanismo de la herencia, siguen vivas y activas, en pares, al interior de las familias. Anjelina Tanbo no solo establece que los objetos los conserven sus padres, sino que también quiere que, a la muerte de ellos, las aquillas sean heredadas por sus hijos Juan y Constanza. O bien el caso de Luisa Tari, natural del pueblo de Yanaoca e india de la encomienda de Pedro Alonso Carrasco quien, en su testamento fechado en

1 Archivo Regional del Cusco (ARC) Antonio Sánchez Protocolo $\mathrm{N}^{\circ}$ 30, 1583-1585, f. 500v. Paleografía de Eliana López.

2 ARC, Pedro de la Carrera Ron Protocolo N ${ }^{\circ}$ 5, 15861596, f. 697v. Paleografía de Carolina Odone.
1597, expone: "yten declaro por uienes myos dose/ aquillas de plata q[ue] pessan diez $\mathrm{p}$ [eso]s/ las quales se hallaran en mi caxa/". ${ }^{3}$ Esta mujer posee además 90 vacas, topos de tierra en el pueblo de Yanaoca, dos pares de topos de plata grandes y prendas textiles. No es posible saber cómo adquirió sus doce aquillas, considerando que no es un número menor de objetos. ¿Las habrá adquirido por herencia, por compra? De haber sido adquiridas por compra, una posibilidad sería la almoneda pública o venta de objetos a modo de remate (Odone y Durán, 2017, p. 47). Tampoco es posible saber si las aquillas de Luisa Tari eran de tiempos antiguos o de factura colonial. Se plantea esta interrogante puesto que las aquillas coloniales "fueron muy decoradas en el tercio superior, no solo con estilos geométricos sino que también con representaciones cotidianas" (Vetter, 2016b, p. 129).

Ana Cochauto en su testamento de $1589^{4}$ señalaba que: "un yunga llamado melchor se me deue/ çinco pesos por rrazon que le di para que me hiziera unos/ cocos mando se cobre hecho por hazer y se de para/ mi hija catalina chumbe callis". ${ }^{5}$ A su vez, en su inventario de bienes, también de 1589 , se señalaban "otros dos cocos de plata que dizen los albaceas / los tiene un yunga [platero] que seade cobrar/". ${ }^{6}$ Esta referencia documental resulta significativa puesto que está indicando un contexto de producción: el platero yunga llamado Melchor, quien además trabajaba las aquillas en patrón de a pares. No es de extrañar que fuera un platero indígena quien elaborase las aquillas que Ana Cochauto le había solicitado, pues se permitía su factura siempre y cuando no fuesen objetos de idolatría (Vetter, 2016b, p. 88).

Melchor remite directamente a los orfebres yungas

3 ARC, Antonio de Salas Protocolo N 18, 1595-1597, f. 727v. Paleografía de Vicente González.

4 En el ARC existe un testamento y un inventario de bienes de Ana Cochauto. El testamento está fechado el 4 de octubre y el inventario, el primero de diciembre. Ana falleció entre octubre y diciembre de viruela. El inventario fue presentado por sus albaceas, Vicente Quispi coro [sic] y Martin Atauche. Ambos documentos forman parte de Pedro Carrera Ron Protocolo $\mathrm{N}^{\circ} 5$, 1586-1596.

5 ARC, Pedro Carrera Ron Protocolo N 5, 1586-1596, Testamento, f. 868v. Paleografía de Eliana López.

6 ARC, Pedro Carrera Ron Protocolo N 5, 1586-1596, Inventario, f. 270r. Paleografía de Carolina Odone. 
trasladados a Cusco y que justamente trabajaban, en época prehispánica, los objetos de plata para la élite indígena. En una relación de plateros indígenas del Cusco del siglo XVI se nombra como orfebres a una serie de indios yungas. En esa lista no aparece Melchor, pero sí Martin Manya, Marcos Ucani, Lucas Sacayco o Cacayco, Alonso Sacayco, su nieto Alonso Sacayco, Gonzalo Sacayco y Pascual Sacayco (Vetter, 2008, p. 123). ¿Se trataría de un ayllu de plateros yungas? No se cuenta con mayores antecedentes para responder esta pregunta de forma afirmativa, pero sí se reconoce que entre ellos existen lazos de parentesco y que el oficio se transmitía familiarmente, lo que remite a un modo de producción étnico y conformado por artífices plateros especializados.

Un ejemplo similar, aunque para las primeras décadas del siglo XVII, corresponde a los plateros indígenas Diego Massi, Francisco Chuqui y Diego Guamani, que estaban unidos por lazos de parentesco: "diego massi y [francisco] chuqui her / manos y a diego guamani / primo hermano de los / suso [dichos]", 7 y cuyos padres también fueron plateros: "y que son hijos de alonsso massa / y pedro bilca yndios plateros muy primos". ${ }^{8}$ Ellos residían en el pueblo de Pampamarca, situado en la provincia o repartimiento de los Canas. ¿Podría pensarse que en Pampamarca había ayllus de plateros indígenas especializados, al igual que en Cusco, Colquepata y Paucarparta, en la producción de aquillas coloniales? Pensamos que sí (Vetter, 2016b, pp. 131-132).

El trabajo de los carpinteros indígenas, al igual que el de los plateros, era considerado por los hispanos una labor ejecutada por "indios muy primos, y curiosos en sus officios" (Vásquez de Espinosa, 1948 [1628-1629], p. 556). ¿Sería posible pensar que la expresión indios muy primos y curiosos, para los carpinteros, apuntaría a formas de trabajo a la usanza antigua, a la destreza de los qerocamayoc, a la especialización alcanzada por aprendizajes acumulados y heredados por generaciones? En el contexto en el que es aplicada la expresión de indios muy primos $y$ curiosos se sugiere que se estaría aludiendo a los que

7 Archivo Regional del Cusco (ARC), Corregimiento Legajo 7 Cuaderno 12, 1624, f. 1r y f. 3r. Paleografía de Vicente González.

8 ARC, Corregimiento Legajo 7 Cuaderno 12, 1624, f. 6r. Paleografía de Vicente González. hacen su trabajo cuidadosamente [curiosos] y excelente $[$ primos].?

Los carpinteros indígenas se reunían en torno a la cofradía de San José de la Iglesia Catedral, además de la parroquia de Santa Ana. Esa hermandad era la que representaba a "los Maestros Naturales del 'Gremio de Carpinteros, Fabricadores de Instrumentos y Ruequeros"', tales como Feliciano Salas, Matías Soncos, Blas Orcohuaranca, Nicolás Quispe y Evaristo Valenzuela, empadronados en torno a la parroquia de Santa Ana (Gutiérrez, 1979, pp. 4-5). Es el caso también de Domingo Inquil, indio natural de la parroquia de San Cristóbal, de oficio carpintero, quien en 1650 tenía sus propios oficiales y herramientas y efectuaba contratos y/o asientos de trabajo en el ámbito de la iglesia y hospital de mujeres de San Andrés (Revista del Archivo Histórico del Cuzco, 3, 1952, p. 72).

No hay una documentación abundante sobre contextos de producción de qeros, aunque sí hay una gran cantidad de ellos. ${ }^{10}$ En tiempos coloniales seguían siendo objetos muy estimados, incluso en contextos geográficos muy distantes de Cusco, como la ciudad colonial de Santiago de Chile donde se menciona que existían "unas taças en que veven los indios a husança del Cuzco" (Testamento de Ana de Salazar, originaria de La Serena, citado en Valenzuela, 2010, p. 239). Incluso fray Diego de Ocaña durante su viaje a Cusco, en 1603, pintó un "traje de las pallas reynas y indias principales mugeres de caciques" portando en sus manos dos objetos, "aquel vaso / q[ue] tiene en la mano se llama quero con que dan / de beber la chicha a los indios, y ellas en los bay / les usan de aquel tanborino" (1599-1605, f. 335). Al respecto Cummins refiere que "el retrato de Ocaña demuestra incuestionablemente que a comienzos del siglo XVII los queros se pintaban íntegramente y luego eran usados por las elites incaicas. Más aún, el diseño probablemente es uno que Ocańa vio en el Cuzco, pues es sumamente parecido al de varios queros pintados que se han encontrado" (2005, pp. 29-30).

9 Peter Mason, com. pers., 2015. Haciéndose hincapié en que su trabajo llama la atención, es diferente, extraño pero interesante, José Luis Martínez C., com. pers., 2015.

10 Se señala que la cantidad de qeros existente en diferentes museos es extraordinaria (Martínez et al., 2016, p. 19). 
En Cusco los qeros seguían circulando entre las gentes indias. Como en el caso de los que, en 1590, conservaba "Ju[an] gualpa succo ynga cacique principal de la parro/quia del ospital de naturales de la ciudad del cuzco/ hijo de usno [sic] descendiente de uiracocha ynga y de maria/ chisquisuyo ya difundos". ${ }^{11}$ Juan Gualpa dejó algunos de sus bienes claramente repartidos: "yten mando al d[ic]ho don her[nan]do gualpa tito mi hijo/ dos pares de queros que dizen el un pares, de chonta/ y el otro de ńaccha". ${ }^{12}$ Esta descripción de qeros de chonta y ñaccha fue abordada por Gabriela Ramos (2005, p. 55). Para el primero propone dos posibles significados: 1) qero de chonta refiere al vaso de madera de chunta y/o palmera, árbol de una madera firme y flexible, propio de la vertiente oriental andina. 2) qero de chonta refiere al tipo de dibujos que tiene el vaso, en este caso, palmeras. Respecto de qero de ńaccha, Ramos no ha podido vincular el vocablo con un tipo de madera particular y lo asocia con el significado de peine $(2005$, p. 65$)$, siguiendo el vocabulario quechua de González Holguín (1989 [1608], p. 303). En el Diccionario de la Academia Mayor de la Lengua Quechua solo se consigna la voz ñachá, "adv. Ya (de algo que ya debió haber ocurrido)” (2005, p. 351).

El kuraca Juan Gualpa declaraba ser descendiente de una antigua panaca incaica y haber recibido su cargo

\section{[...] por m[er]ced del conde de uillar uirrei/} que fue estos rreynos el cacicasgo principal de la d[ic]ha/ perroquia [sic] y en particular que tengo de cien $y[$ ndio]s que el bi/rrey don fran[cis]co de toledio me dio a mi cargo como pare/çera por el padron de la $\mathrm{d}[\mathrm{ic}] \mathrm{ha}$ parroquia los quales $\mathrm{d}[\mathrm{ic}]$ hos/ cargos me dieron por seruicios que e hecho a dios $\mathrm{n}[\mathrm{u}$ est] $\mathrm{ro} /$ señor y a su mag[esta]d y que mis pasados eran gouernadores/ de la prouincia de andesuyo. ${ }^{13}$

11 Archivo Regional de Cusco (ARC), Pedro de la Carrera Ron Protocolo N 5 , 1586-1596, f. 873v. Paleografía de Eliana López.

12 ARC, Pedro de la Carrera Ron Protocolo N ${ }^{\circ}$ 5, 15861596, f. 874v. Paleografía de Eliana López.

13 ARC, Pedro de la Carrera Ron Protocolo N ${ }^{\circ}$ 5, $1586-$ 1596, f. 876r. Paleografía de Eliana López.
Juan Gualpa nombró a su hijo Hernando Gualpa Tito como "sibçesor en los d[ic] hos cargos", ${ }^{14}$ siendo significativo que fuera justamente él quien conservara dos pares de qeros, uno de chonta y otro de ñaccha, lo que indica claramente que los objetos siguen en manos de élites nativas, legitimándolas en tanto autoridades de poder, aunque hayan sido instaladas por los hispanos. Otro aspecto interesante de los qeros de Juan Gualpa es que permiten pensar que existen diferenciaciones entre ellos, puesto que no todos son nombrados de la misma manera.

El testamento de Ana Cochauto igualmente hace pensar que existen distintos tipos de qeros, lo que podría asociarse también a distintos usos: "unos queros grandes llamados/ uritu ${ }^{15}$ mando sede para mi hija fran[cis] ca" ${ }^{16}$ Existía también otro vocablo aplicado a los qeros grandes, tal como Pedro Cancho señalaba en su testamento de 1589: "mando para el $\mathrm{d}[\mathrm{ic}]$ ho j[uan] cancho mi hijo/ dos baços grandes pintados que llaman urpe ${ }^{17}$ [sic] y otro/ baço para la d[ic]ha mi hija_// yten tengo otro baço de palo mando para ana mi hija y otros/ dos basos pequeños de palo para fran[cisc]a mi hija_/". ${ }^{18}$

Pedro Cancho tenía varios tipos de qeros. Por una parte, qeros grandes llamados urpe, los que fueron heredados por su hijo Juan Cancho, en patrón de pares. Solo una de sus hijas heredó qeros a pares, con la característica de que estos eran pequeños. $Y$ otra de sus hijas solo conservó un qero, por ende no en patrón de pares.

14 ARC, Pedro de la Carrera Ron Protocolo N 5, 15861596, f. 876r. Paleografía de Eliana López.

15 “Vritu. Papagayo" (González Holguín, 1989 [1608], p. 357).

16 ARC, Pedro de la Carrera Ron Protocolo N 5, 15861596, f. 868v. Paleografía de Eliana López.

17 "Vrppu: Cántaro muy grande mayor que ttico" (González Holguín, 1989 [1608], p. 356). “Urpu. S. Cántaro o vasija grande de arcilla cocida, de forma alargada, de cuerpo ensanchado y de boca angosta, en que se hace fermentar la chicha" (Diccionario de la Academia Mayor, 2005, p. 692).

18 ARC, Pedro de la Carrera Ron Protocolo N 5, 1595, fs. 861r-v. Paleografía de Eliana López. 
En el testamento de Alonso Hanco, fechado en 1586, se reconoce: "yten declaro que tengo tres pares de quiros pin/tados en que yo beuia mando que lo goçe mi cuñado/ diego tanpu orcuuaranca”. ${ }^{19}$ En 1590 en el inventario de bienes de Maria Chuqye Samay, adscrita a la parroquia de Nuestra Señora de la Purificación del Hospital de Naturales, se señala que tiene "/ quatro pares de baços de madera / [...]", además "dos pares de mates debeuer y ottros dos pares de mates de comer//". ${ }^{20}$ Como también ocurre con Catalina Poco o Puca, quien en su testamento de 1571 seńala que "tengo vn carnero de la [tierra] y vn col / chon y tres pares de mates y dos cantaros". ${ }^{21}$

Las referencias documentales presentadas respecto del distrito urbano de Cusco permiten pensar en la presencia, uso y circulación de aquillas y/o cocos de plata, además de matis para beber, vasos de madera y qeros grandes y pequeños, algunos pintados y otros solo consignados como qeros o vasos para beber. Los objetos eran conservados entre los señores naturales y las unidades familiares, sin distinguirse claramente patrones que permitan reconocer cuáles eran los mecanismos de herencia que estaban funcionando.

\section{Presencia de aquillas, qeros y matis en la costa-valle-sur-del Perú}

En 1535 los indígenas de Atico y Caravelí pertenecían a la encomienda de Cristóbal de Burgos. Sus kuracas eran "Raca y su hermano Roca Señor del pueblo de Atico y Caraveli con todos sus yndios DCC yns." (Provisión expedida en el Cuzco el 3 de julio de 1535, citado en Málaga, 1975, p. 63). En 1540 la encomienda se traspasó a Juan López de Recalde y, luego de las guerras civiles, el licenciado Pedro de La Gasca, en 1548, entregó esa encomienda a Hernando Álvarez de Carmona, residente en la ciudad de Arequipa, quien también era encomende-

19 ARC, Pedro de la Carrera Ron Protocolo N ${ }^{\circ}$ 5, 15861596, f. 694r. Paleografía de Eliana López.

20 ARC, Pedro de la Carrera Ron Protocolo N 5, 15861596, f. 41r. Paleografía de Vicente González.

21 ARC, Antonio Sánchez Protocolo N²2, 1570-1572, f. 63r. Paleografía de Álvaro Durán. ro de "un grupo de mitmaq de Aymaraes"22 (Pease, 1982, p. 111).

En la visita de 1549 se señalaba que "dan los yndios del Repartimiento de Caraveli a mi Juan López de Recalde y de lo que me acostumbran a dar agora de presente: [...] Dan cada quatro meses trezientos pares de mates pintados" (Visita de Atico y Caravelí 1549, en Galdós, 1975-1976, p. 75, f. 2r, negritas nuestras). Es decir, 1.200 pares de mates pintados al ańo, ${ }^{23}$ cifra significativa, lo que permite plantear que el espacio de Caravelí, a partir de la década de 1540, era un activo centro de elaboración de mates pintados, producción controlada primero por el encomendero López de Recalde o Ricaldi y luego por Álvarez Carmona, residente en la ciudad de Arequipa.

Actualmente no se cuenta con información que permita identificar cómo se confeccionaban esos 1.200 pares de mates pintados. Sin embargo, en la visita se informaba que en el área de Caravelí había un "pueblo de los mates Tres Casas III Tres ys. III" (Visita de Atico y Caravelí 1549 en Galdós, 1975-1976, p. 80 , f. $5 \mathrm{v}$, negritas nuestras). La referencia del pueblo de los mates con tres casas y tres indios lleva a pensar en tiempos del Tawantinsuyu cuando:

[...] para cada oficio había un pueblo o dos o tres señalados conforme al oficio, los cuales tenían cuidado de dar hombres hábiles y fieles que, en número bastante, sirviesen aquellos oficios remudándose de tantos a tantos días, semanas o meses. Y este era el tributo de aquellos pueblos (Garcilaso de la Vega, I. (1991) [1609], Lib. 6, Cap. III, p. 333).

Claramente el pueblo de los mates de Caravelí era un ayllu de producción especializado y activo en tiempos

22 En la década de 1560 se iniciaron una serie de juicios en torno a la posesión de la encomienda de Atico y Caravelí, enfrentándose un hijo de Juan López de Ricalde con Álvarez Carmona, quedando en el año de 1566 la encomienda en manos de este último, quien además, en el Corregimiento de Camaná, tenía la encomienda de los indios del repartimiento de Molleguaca (Málaga, 1975, pp. 63-64).

23 Tres entregas al año, cada cuatro meses, darían un total de 1.200 mates pintados al ańo. 
coloniales, siendo además significativo que el nombre del poblado fuese el mismo que el objeto que producían sus artífices.

Pero no solo los habitantes del espacio de Caravelí confeccionaban mates pintados; también en la visita se informaba de un segundo colectivo social, los Aymaraes que "quedaron que darían [...] ciento y sinquenta pares de mates pintados" (Visita de Atico y Caravelí 1549, en Galdós, 1975-1976, p.75, f. 2r, negritas nuestras). El kuraca Guaman Gagia señalaba que entregaban "a Carmona [...] CL mates, cada cuatro meses" (Visita de Atico y Caravelí 1549, en Galdós, 1975-1976, p 79, f. 4v), es decir, 450 pares de mates pintados al año.

No se cuenta con datos que permitan identificar dónde y cómo se confeccionaban esos 450 pares de mates pintados al ańo. Relataba su kuraca que ellos "solian trebutar al Ynga y a los señores que han tenido. Dixeron que le solian dar (entre líneas: al Ynga) Ropa de cunbe y lana y plumas y le / guardaban ganado, y le daban charque, ojotas y mates y para su servicio le daban vein/te yndios en el Cuzco" (Visita de Atico y Caravelí 1549, en Galdós, 1975-1976, p 79, f. 4v, negritas nuestras). Estos mitmaq Aymaraes en tiempos del Inca entregaban mates, y en tiempos hispanos, mates pintados. ¿Podría pensarse que se trata de qeros ya que prehispánicamente los matis, en general, eran pirograbados? ¿Es solo una omisión fortuita el paso de la entrega comunitaria de mates en tiempos prehispánicos a la entrega comunitaria de mates pintados en tiempos coloniales? ${ }^{24}$ ¿A quién estaba dirigida esa producción de matis y/o qeros?

En tiempos del Inca, los mates circulaban por un amplio espacio, identificándose que, desde el área del valle costero de Chincha hacia el Collao, existía un organizado intercambio de estos entre la costa y la sierra, particularmente hacia Chucuito (Rostworowski, 1970, p. 157; Masuda, 1982, p. 97). El cronista Lizárraga relataba, refiriéndose justamente al valle de Chincha que, durante el Tawantinsuyu "los mercaderes tenían licencia de discurrir por este reino con sus mercadurías, que las principales eran mates para beber, muy pintados y tenidos en mucho, hasta la provincia de Chucuito" (2002 [1594-1607],

24 José Luis Martínez C., com. pers., 2015. p. 134). A partir de los estudios que plantean que el sistema de la economía colonial fue capaz de integrar, en los nuevos mercados internos, modos indios de producción y consumo, es dable pensar que los españoles hubiesen controlado la producción de mates para comercializarlos entre indígenas (Assadourian, 1982; Glave, 1989). Un ejemplo de ello es Francisca Palla, quien en 1564 conservaba 23 mates de calabaza pequeños y medianos, además de tres mates de calabaza pintada (Odone y Durán, 2017).

A su vez, José Luis Martínez (2012) propone que también el manejo o control hispano sobre la producción de matis estaba dirigido a importantes autoridades coloniales como el virrey Francisco de Toledo, quien envió a España "Dos vassos de calabaza, pequeños que llaman mates, el hueco dellos guarnecido de plata y por fuera pintados de animales, frutas y pájaros en que bebían los ingas" (Inventarios Reales, Real Palacio de Madrid, 1600, Transcripción de los manuscritos del Archivo del Palacio Real, por Francisco J. Sánchez Cantón, en el Instituto Diego Velázquez, Madrid, folio 239 citado por Martínez, 2012, p. 185).

No solo mates pintados circulaban en Arequipa, también aquillas. Interesante es el caso de Francisca Palla, quien tenía "seis cocos de plata" y "un coco de plata marcado que es el questá empeñado en veinte pesos del cacique de Chávez ciento y treinta e un pesos de plata corriente". ${ }^{25}$ Es muy probable que $\mathrm{Pa}$ lla fuese comerciante y prestamista, lo que explicaría la amplia gama y cantidad de objetos de indios que se registran en su testamento e inventario de bienes (Odone y Durán, 2017). Respecto de las aquillas, claramente las adquirió al ser estas dejadas en prenda y como parte de pago. A su vez, el que la aquilla estuviese marcada está indicando su elaboración colonial, ya que los objetos de plata y de oro tenían que tener obligatoriamente la marca del Quinto Real (Relaciones de los Virreyes y Audiencias que han gobernado el Perú. Memorial y Ordenanzas de D. Francisco de Toledo. Tomo I, 1867 [1569-1574], pp. 102-103; Quiroz, 2008; Vetter, 2016b).

25 Archivo Regional de Arequipa (ARA), Juan de Torres Protocolo $\mathrm{N}^{\circ} 84,1564$, f. 3v. Paleografía de Carolina Odone y Álvaro Durán. 
Francisca Tia en su testamento declaraba "una/aquilla de saya ${ }^{26}$ [sic] entrapada [sic] con supa/samano de plata". ${ }^{27}$ Ella la tenía empeñada y lo único que deseaba era recuperarla. Ana Choncaya en 1586 declaraba en su testamento que tenía "dos pares de cocos de plata". ${ }^{28}$ Ana Chuquirima tenía "trescocos deplata uno grande y dos pequeńos". ${ }^{29}$ A su vez, Lorenzo Tupache declaraba "seis pares de aquillas de plata", los que heredó a sus hijos Joan y Nicolas Tupache. ${ }^{30}$

Francisca Palla conservaba 16 qeros pintados pequeños y grandes (Odone y Durán, 2017, p. 62). Barbola Poco en 1588 declaraba en su testamento que tenía "dos pares de queros". ${ }^{31}$ Y Juan Guacondori, originario del pueblo de Yamque Collaguas, conservaba "dos queros grandes con que beben los yndios". ${ }^{32}$

Algunos de estos objetos, siguiendo el patrón de a pares, fueron traspasados como herencia y conservados al interior de las unidades familiares. También ocurría que cuando no existían descendientes directos, los qeros, aquillas y matis eran rematados en almoneda pública, surgiendo nuevos poseedores tanto españoles como indígenas. Este hecho posibilita pensar que la muerte de quien posee objetos prehispánicos inaugura nuevos circuitos de desplazamiento para estos, no necesariamente en manos andinas, sino que españolas, abriéndose nuevos contextos de uso, no sabemos si mercantiles y/o suntuarios (Odone y Durán, 2017).

Otro contexto de circulación interesante es el que se observa en el testamento del cura Pedro de Portugal

26 "Saya. s. Hist. Mitad de arriba o de abajo, mitad derecha o izquierda, en la organización dual diametral andina. || Tamaño o altura de objetos en posición vertical" (Diccionario de la Academia Mayor, 2005, p. 692).

27 ARA, Sebastián Mariño Protocolo $\mathrm{N}^{\circ}$ 187, 1611, f. 166r. Paleografía de Eliana López.

28 ARA, Antonio de Herrera Protocolo $N^{\circ}$ 49, 1586, f. 290v. Paleografía de Tania Zúñiga.

29 ARA, García Muñoz Madueño Protocolo $N^{\circ} 201$, 1606, f. 102r. Paleografía de Carolina Odone.

30 ARA, García Muñoz Madueño Protocolo No 201, 1607, f. 102r. Paleografía de Carolina Odone.

31 ARA, Antonio de Herrera Protocolo $N^{\circ} 49,1586$, f. 221r. Paleografía de Tania Zúńiga.

32 ARA, Diego Navarro Protocolo $N^{\circ}$ 81, 1586, f. $164 \mathrm{r}$. Paleografía de Carolina Odone.
Torres, fechado en 1698 en el pueblo de Andagua, donde se declaran "dos basos de plata pequeños [que] llaman / aquillas". ${ }^{33}$ Pedro de Portugal Torres fue vicario del pueblo de Andagua y también comisario de la Santa Cruzada. ¿Sería dable pensar que las aquillas mencionadas fueron obtenidas en contextos de recuperación de 'objetos de indios' por campańas de extirpación de idolatrías? Es muy probable, puesto que el obispo de Arequipa Pedro de Villagómez daba cuenta de que los indios "mantenían clandestinamente prácticas religiosas prehispánicas [...]. Cerca de Caravelí, Villagómez dijo haber hallado tres mil tumbas de ancestros que aún recibían las ofrendas de sus comunidades" (Marsi1li, 2014, p. 63). Existe otra serie de indicios que muestran que en otras áreas, como en la provincia de Huarochiri, se requisaron objetos de indios en contextos de extirpación de idolatrías. Es el caso de los indios yauyos de la doctrina de San Cristóbal, a quienes se les quitaron "todas las galanterías y baxillas de plata y topos y rropa con que ellos en las fiestas cantan y dansan y baylan, como aquilla" (Guaman Poma, 1980 [1615-1616]. Tomo III, p. 1012, negritas nuestras). Algo similar ocurrió en el pueblo de San Felipe, por donde pasó el visitador Francisco de Ávila y donde se le quitaron a los indios "aquillas, todo de plata y de oro. Los quales tenían para dansar y holgar en las fiestas y pasquas, Corpus Criste del ańo y se los a lleuado todo de los pobres yndios" (Guaman Poma, 1980 [1615-1616]. Tomo III, p. 1022, negritas nuestras).

Para la segunda mitad del siglo XVIII, existe un interesante documento sobre la acusación del kuraca de Andagua Gregorio Taco, acusado de realizar prácticas idolátricas y oraculares para recordar y reverenciar a los ancestros en peñas, cuevas, mochaderos y/o adoratorios. En el expediente del caso se identificaron objetos para libaciones como limetas o vasijas de vidrio para chicha, algunas procedentes de Cusco, junto a mates, vasijas de barro y mates guarnecidos en plata vieja (Galdames y Marsilli (Comps.) 2012; Takahashi Martínez, 2012). ${ }^{34}$

33 Archivo Arzobispal de Arequipa (AAA), Vicarías, Condesuyos, Andaguas 2, Testamento de Pedro de Portugal de Torres, 1698, f. 1r. Paleografía de Álvaro Durán y Vicente González.

34 En ambas publicaciones se encuentra el interesante documento paleografiado. Como reseńan los autores 


\section{Sobre la presencia de aquillas, qeros y matis en el urcosuyu o borde occidental del lago Titikaka}

En 1548 Diego de Peralta recibió la encomienda del repartimiento de Capachica, que formaba parte del Corregimiento de Chucuito. Cuatro eran los indios principales: "uno Apasca y otro Sucanque, naturales de Capachica y otro Ecachi platero y otro Guanca de la isla Taquiri, subjetos al cacique don Diego de Capachica” (La tasa toledana de Capachica, en Rostworowski, 2005 [1993], p. 365, f. 308v, negritas nuestras). Resulta singular que un indio principal, Ecachi, fuese platero, lo que permite preguntarse sobre la posible fabricación de objetos de plata, ¿aquillas, por ejemplo?, por parte de señores étnicos.

La provincia de Chucuito en la década de 1560 ya destacaba como un nodo de producción y circulación de materias primas, productos, mercancías y oficios, integrando ciudades relativamente distantes como Moquegua, Arequipa, La Paz, Potosí y Cusco, entre otras. Importante era la presencia de albañiles, plateros, olleros, carpinteros, rescatadores o trajinantes, entre otros oficios realizados por indígenas, además de la circulación de maderas y ornamentos para la construcción de iglesias y capillas a cargo de autoridades nativas, las que organizaban y distribuían la mano de obra indígena. Moquegua y Larecaja habrían constituido los lugares de extracción de madera utilizada, principalmente, en la construcción de iglesias. Albañiles, canteros, labradores de paredes y carpinteros indígenas, pagados por los caciques, eran los encargados de construirlas y ornamentarlas (Murra, 1964; Glave, 1989).

En relación a los oficios de plateros, en la visita de 1567 se da cuenta de la existencia de ayllus especializados, lo que permite pensar en la permanencia de formas o modos de producción a la usanza indígena. El kuraca de Chucuito-Anansaya, Martin Cari declaraba al visitador que habían "diez ayllos de indios aymaraes [...] y hay otros dos ayllos uno de plateros

respectivos, el documento se encuentra en el Archivo Arzobispal de Arequipa, sección Vicarías, serie Condesuyos, subserie Andagua. Tiene por título Expediente Penal Serie Idolatrías, Gregorio Taco, Legajo de 636 folios, año 1751. y otro de olleros" (Diez de San Miguel, Visita hecha a la provincia de Chucuito 1567, p.14, f. 6r).

A su vez, el cacique principal de Chucuito-Urinsaya, Martin Cusi declaraba como "pueblos" de oficios especializados a "Sunacaye pueblo de plateros y Cupi pueblos de olleros" (Diez de San Miguel, Visita hecha a la provincia de Chucuito 1567, p. 27. f. 12v). De acuerdo a Gabriel Martínez, serían "Sunacaya y Cupí -los pueblos de artesanos de status especial" (1989, p. 150).

Pero no solo en Chucuito se identificaron ayllus de plateros y olleros, sino que también en el pueblo de Acora-Anansaya y Urinsaya (Diez de San Miguel, Visita hecha a la provincia de Chucuito 1567, p. 91, f. $44 v$ y 98, f. 48r, respectivamente). Distingue además Gabriel Martínez (1981) los ayllus de Umachuco y Calhala, respectivamente, como de olleros y plateros, igualmente parte de las tierras de Acora.

A Luis Cutipa, "encargado de miles de animales de urinsaya" (Murra, 2002, p. 317), se le preguntó "qué tributo y servicio daban al cacique principal de esta parcialidad de Lurinsaya en tiempo del ynga o si el ynga le daba alguna cosa para su sustentación" (Diez de San Miguel, Visita hecha a la provincia de Chucuito, 1567, p. 81, f. 39r). Respondiendo "que el ynga le daba algunas veces algún vestido o otra cosa de precio y algunas ovejas y alguna pieza con qué bebiese" (Diez de San Miguel, Visita hecha a la provincia de Chucuito, 1567, p. 81, f. 39r, negritas nuestras). Se sugiere que se trataría de una pieza de plata para beber o aquilla.

También se declaraba que en tiempos del Inca, se daba como tributo "un barniz colorado llamado limpi” (Diez de San Miguel, Visita hecha a la provincia de Chucuito, 1567, p. 39, f. 18v). Ya ha sido abordado el significado del vocablo limpi/llimpi y su asociación con los llimpikuna o llimppicuna, artífices en embellecer los qeros con colores (Martínez y Martínez, 2013, p. 73). ¿Es que el limpi/ llimpi lupaqa estaría orientado a embellecer vasos de madera?

Las referencias a circulación de "colores" entre gentes indígenas en áreas del altiplano central de Bolivia son detectables entre los Pacajes urcosuyu. 
Las evidencias señalan que en los poblados de Guaqui, San Jesús de Machaca la chica, Caquigora, Calacoto y Caquiaviri, en tiempos hispanos tempranos, se les entregaban colores y lana a los indígenas para la elaboración de piezas de ropa, no especificándose de qué colores o tipos se trataba (Saignes, 1980). Ciertamente que los colores estarían asociados a la confección de textiles, mas surge la interrogante de si, antes de la tributación hispana, esa circulación de colores pudiera estar asociada a contextos de producción no necesariamente textiles. Se ha abordado, para el altiplano sur de Bolivia, en territorio Lipes, la importancia de la circulación de colores dada la existencia de minas de colores finos, mandando Thupaq Inka Yupanqui que en ello tributasen, subrayándose que procedían de minerales (Martínez, 1995, p. 37; 2011, p. 301). La tributación de los Lipes en 1550 incluía "cada seis meses, 30 bolsitas de limpi, 'del tamaño que las soleis dar' en la Villa de La Plata o en Potosi”' (CNM-AH; Cajas Reales 1 f. 56/1550, citado en Gil García, 2009, p. 355).

\section{Sobre la presencia de aquillas, qeros y matis en la ciudad de Nuestra Seńora de La Paz o Chuquiabo}

En 1569 los visitadores Diego de Cangas y Bartolomé de Otazu describen que en el repartimiento de los pueblos de Songo/Sonqo, en los yungas de La Paz, los indígenas se ocupaban de:

[...] labrar las dichas chacaras y comer y beber y holgarse en sus fiestas y regocijos que tienen por ser tan ricos los dichos yndios andan vestidos de terciopelo de damasco y raso las mantas y camisetas con chipanas y brazaletes y anillos y chucos de oro y plata y beben con mates de oro y plata y traen mucha plumería por donde se entiende la mucha posibilidad que tienen para poder pagar doblada tasa de la que pagan (Murra (Comp.) (1991 [1568-1570]), p. 246, f. 288r, negritas nuestras).

Ese beber en mates de oro y plata permite preguntarse si estos corresponderían a aquillas propiamente tal, o bien para áreas de yungas, los mates de oro y plata refieren solo a la forma de los matis o vasos de calabaza.

De manera relativamente contemporánea, la documentación hispana da cuenta de que en la ciudad de La Paz, "las costumbres de la gente deste asiento y provincia es casi como las demás deste reino, porque todos de ordinario se emborrachan con una bebida que hacen del maíz" (Descripción y relación de la ciudad de La Paz 1586, en Jiménez de la Espada, 1965. Tomo I, p. 346). Y para esas borracheras "se juntan en cuadrillas en casas particulares, haciendo unas danzas y bailes con atambores y instrumentos torpes" (Descripción y relación de la ciudad de La Paz 1586, en Jiménez de la Espada, 1965. Tomo I, p. 346).

Es significativo reconocer la reproducción social y simbólica de costumbres antiguas en espacios urbanos domiciliarios y que ese beber a la usanza era acompañado por músicas y bailes. Otro aspecto interesante es que:

[...] nunca bebe ninguno destos indios esta bebida solo, sino que tienen todos los vasos a pares, y habiendo de beber el uno en uno de los dichos vasos, ha de dar de beber al compañero en el otro. Redundan destas borracheras que cometen muchos estupros e incestos con madres, hijas, hermanas, sobrinas y cuñadas, y vuelven a sus ritos y adoraciones antiguas (Descripción y relación de la ciudad de La Paz 1586, en Jiménez de la Espada, 1965. Tomo I, p. 346, negritas nuestras).

¿Es posible entonces reconocer la permanencia no solo de una usanza indígena del beber, sino que también del uso de qeros igualmente a la usanza indígena? Se considera que sí. A comienzos del siglo XVII, y también para La Paz, fray Diego de Ocaña observa que "/ usan de bayles con tamboriles, y ban las indias de / dos en dos y el tamboril en medio y beben mucha / chicha de maíz, y se emborrachan mucho, y las / mujeres también /" (1599-1605, fs. $313 \mathrm{v}-314 \mathrm{r}){ }^{35}$

35 En relación al beber en Potosí, se relata "/la vebida ordinaria de q[ue] todos los indios ansi de/ potossi como de todo el piru usan se llama chi /cha [...]. / es tan fuerte 
Junto a los vasos de madera también se usan y circulan los vasos de plata, posiblemente aquillas, los tachos de plata y las tembladeras. Ana Carrasco, mestiza residente en la ciudad de La Paz, hija de Nicolás Carrasco y María Sissa, declaraba en su testamento fechado en 1704, que le debe un "/ yndio mañaso [sic] sinquenta $\mathrm{p}$ [es]os que le preste en re / ales mando se le cobren boluiendose las prendas / que son dos tembladeras y otro baso de plata/". ${ }^{36}$ Isabel Mallqui, natural de la parroquia de Santa Bárbara, del ayllo Inga de la ciudad de La Paz, declaraba en 1707 "un tacho de plata". ${ }^{37}$

Entre los bienes que se declaran llama la atención el vocablo tallaclla, ${ }^{38}$ objeto aparentemente asociado a tacho, tal como refiere Juan o Julian de Criales, natural de la ciudad de La Paz, quien se casó en el "pueblo de Haiohayo provincia de Sicasica con Doña / Ana Muriel", a quien le entregaron por dote objetos "del tiempo antiguo", destacándose "=un tacho=una tallaclla/". ${ }^{39}$ Las tallacllas estarían circulando a través de herencia entre mujeres, como ocurre con Ana Coronel, originaria de Desaguadero, de la provincia de Pacajes, hija de Sebastián Coronel, natural de Oruro y de Isabel Vela, principal del pueblo de Guaqui. Ana le hereda a su sobrina

q[ue] embriaga, y emborracha mu / cho, y desde el sabbado en la noche hasta / el lunes a mediodía no dexan de veuer / los indios todo este tiempo gastan destama / nera, compran muchas votijas de chicha / les questa cada votija un peso, y juntanse / en un corral todo un ayllo q[ue] es decir to / dos los de una parentela y con un tan / boril en medio de todos q[ue] estan hechos / una rueda dados de las manos unos con otros / andan dançando indios, y indias toda la / noche empesso [sic] sin çessa el baile / hasta q[ue] se acaua la chicha y toda quanta / plata tienen, y a qualquiera ora de la no / che se oyen los tamborines de las ranche/rias y como ban dando bueltas bayla[n] / do ban vebiendo todos ansi varones / como mujeres hasta que se acauan las botijas / de la chicha (Ocaña, 1599-1605, fs. 185v-186r).

36 Archivo La Paz (ALP), Registro de escrituras Testamentos Caja 61 Legajo 93, 1704, f. 525r. Paleografía de Eliana López.

37 ALP, Registro de escrituras Testamentos Caja 63 Legajo 95, 1707, f. 704r. Paleografía de Eliana López.

38 Se ha buscado tanto en el vocabulario quechua de Diego González Holguín (1608) como en el vocabulario aymara de Ludovico Bertonio (1612).

39 ALP, Registro de escrituras Testamentos Caja 63 Legajo 95, 1706, f. 367 v y f. 369r. Paleografía de Eliana López.
Juana Coronel, "dos tallacllas". ${ }^{40}$ Las hay de distintos tamaños, como señala Ynes de Criales, natural de la ciudad de La Paz, quien declara por sus bienes "dos tallacllitas", ${ }^{41}$ además de "dos mates guar / necidos". ${ }^{42}$ En todo caso y respecto de las tallaclla, sería posible aseverar que ellas formarían parte del equipo de beber mate: "yten declaro por mis vienes ocho tallagllas de beber mate y poner asucar y yerua [yerba] con seis / pataguies o bonetes y quatro mates guarnesidos". ${ }^{43}$

Son abundantes, en contextos de inventarios de bienes testamentarios, las referencias a mates guarnecidos en plata con su patagua o pataguay, como lo señala Marcos de Trujillo: "vn mate de gerba [sic] con su pata / guay de plata". ${ }^{44}$ Pataguay, al igual que patagua, haría alusión a una "vasija cilíndrica sobre la que se pone el mate que es una calabacita con que se echa y toma el agua de la yerba" (Egido, 2013, p. 28). Es el soporte del mati y generalmente es de plata. Francisco Valcasar, kuraca principal y gobernador del pueblo de Hato, en la provincia de Omasuyo, natural de este pueblo, declara "vn matte negro guarnecido con / plata, las quales piesas de $\mathrm{d}$ [ic] ha plata labrada paran en mi casa en el / pueblo de Laxa menos un pichel; mas vn poro guarnecido sin tapadera" $^{35}$. O bien Theresa Trujillo, originaria del pueblo de Chulimani, que declara por bienes "un mate barnecido con plata con apar / tados de lo mismo: dos bazos de plata uno / grande y otro chico". 46

Vasos, vasos grandes y pequeños y mates guarnecidos en plata nos conducen al oficio de plateros y a los procesos técnicos implementados: fundir, martillar,

40 ALP, Registro de escrituras Testamentos Caja 64 Legajo 97 (5), 1712, f. 306v. Paleografía de Eliana López.

41 ALP, Registro de escrituras Testamentos Caja 70 Legajo 107, 1723, f. 61v. Paleografía de Eliana López.

42 ALP, Registro de escrituras Testamentos Caja 70 Legajo 107, 1723, f. 62v. Paleografía de Eliana López.

43 ALP, Registro de escrituras Testamentos Caja 71 Legajo 111 (2), 1729, f. 220v-221r. Paleografía de Eliana López.

44 ALP, Registro de escrituras Testamentos Caja 64 Legajo 96, 1711, s/número de foja. Paleografía de Eliana López.

45 ALP, Registro de escrituras Testamentos Caja 64 Legajo 96,1711, f. $109 \mathrm{v}$.

46 ALP, Expedientes Coloniales Caja 129 E27, 1799, f. 3 r. Paleografía de Eliana López. 
laminar, modelar, recortar, repujar. Como el caso del maestro platero Bacilio Tisipura o Tisirupa, que hacía barrilitos de plata para beber agua. Un español le entregaba, para su confección, "dos marcos y / medio de chafalonía con su respectiva / hechura" ${ }^{47}$

Nuevos objetos comienzan a insertarse en la vida de las gentes indias, siendo singular la proliferación de la producción de mates de plata guarnecidos y su adquisición, lo que da cuenta de los cambios, de las nuevas demandas, circulaciones y comercializaciones de la yerba mate que, en el siglo XVIII, era ampliamente consumida en distintos espacios de la Audiencia de Charcas (Assadourian, 1982; Escobari, 2014).

\section{Sobre la presencia de aquillas, qeros y matis en la ciudad de Chuquisaca}

Para las primeras décadas del siglo XVII, Vásquez de Espinoza refiere que en Chuquisaca o La Plata se vendían "vazos de madera. matizados de diferentes colores que llaman queros en que los indios beben su bebida de chicha; $y$ otros muchos generos assí de la tierra, como de mercaderías de España de que es muy abastesida esta ciudad y sus ciudadanos muy lustrosos" (1948 [1628-1629], p. 608, negritas nuestras). Esta observación del cronista respecto de los vasos de madera ya ha sido abordada por Martínez et al. (2016), quienes postulan que se estaría en presencia "de un comercio para los indios. De objetos hechos por indios para indios" (2016, p. 37). Hipótesis que resulta tremendamente sugerente puesto que permite pensar en cómo se fue articulando un mercado interno para cubrir las necesidades de las gentes indias, mercados además donde se ponían producciones que no necesariamente formaban parte de las tributaciones indígenas (Glave, 1989, p. 174).

A su vez, los qeros eran muy estimados a ojos hispanos, como se observa en la tienda del mercader Gonzalo de Figueredo (Martínez et al., 2016, p. 37). ${ }^{48} \mathrm{La}$

47 ALP, Expedientes Coloniales Caja 122 E39, 1795, fs. 2r-v. Paleografía de Eliana López.

48 Al igual que José Luis Martínez et al., (2016) agradecemos a Alejandra Vega el que nos facilitase el documento que forma parte de su proyecto FONDECYT 1120275 , Vestir al indio/vestirse de indio. Vestimenta de los in- tienda se ubicaba en su casa, emplazada en "la entrada de la calle/que va de la plaza desta ciudad hazia el/combento de san francisco". ${ }^{49}$ Tenía un sinnúmero de mercancías de procedencia indígena e hispana, y era impresionante la cantidad de qeros: "sesenta y dos pares de queros/a quinze rreales par monta/ ciento y diez y seis pessos y/dos rreales/" ${ }^{50}{ }^{2} \mathrm{De}$ qué modo el mercader los obtuvo? En el documento se señala que vendía mercancías para el trabajo de artesanos como "brocas de ça/patero [...] agujas de zapa/tero [...]". ${ }^{51}$ A su vez, tenía a artesanos indígenas como deudores: "yten le deue pablo indio sastre [...] yten le deue una yndia muger/de un sedero Melchor [...] yten le deue el platero françisco lopez de/figueredo cura del tambo quemado [...] yten le deue un yndio sedero/llamado carlo". ${ }^{52}$ Si Figueredo tenía vínculos con artesanos/artífices indios, ¿sería posible pensar que, a través de ellos, el mercader accedía a los qeros?

La presencia y circulación de estos objetos también se verifica como parte del repertorio de bienes de mujeres. Era el caso de "María Yuyo, habitante de la ranchería de los yamparaes, donde poseía una casa con medio solar, siendo natural de la Parroquia de San Lázaro, decía ser natural del pueblo de Arabate, cercano a La Plata. María tiene cuentas con numerosos particulares y parece haberse dedicado al comercio de ropa” (Presta, 2010, p. 10). Ella tenía entre su vajilla "dos queros (vasos de madera) grandes" (Presta, 2010, p. 10).

dios del común en la Villa de Potosi (1570 a 1670).

49 Archivo y Biblioteca Nacionales de Bolivia (ABNB), Escribanos Públicos de La Plata EP, 117, Inventario de los bienes de Gonzalo de Figueredo, 1619, f. 52v. Paleografía Eliana López.

50 ABNB, Escribanos Públicos de La Plata EP, 117, Inventario de los bienes de Gonzalo de Figueredo, 1619, f. 65r. Paleografía Eliana López.

51 ABNB, Escribanos Públicos de La Plata EP, 117, Inventario de los bienes de Gonzalo de Figueredo, 1619, f. 61v. Paleografía Eliana López.

52 ABNB, Escribanos Públicos de La Plata EP, 117, Inventario de los bienes de Gonzalo de Figueredo, 1619, f. 68r-v y f. 71v. Paleografía Eliana López. 
Igualmente Élvira [sic] Vásquez, hija de padres indígenas nacidos en la ciudad de La Plata, dedicada al comercio y a los trajines, poseía entre sus efectos personales aquillas. Otro caso es el de Ana Paico, "pulpera y prestamista residente en La Plata". Casada primero con "Fernando Gualparoca, gobernador del pueblo de Guata en el entorno rural de La Plata" (Presta, 2010. p. 11), y posteriormente con Pedro Maquerua, cacique del pueblo de Arabate. Entre sus bienes se consignan "cinco pares de cocos de plata de diferentes tamaños" (Presta, 2010, p. 11).

Ana María Presta analiza los cambios y transformaciones que estos objetos de indios experimentaban en la ciudad de La Plata, sugiriendo que "rotas las barreras del Tawantinsuyu, comenzaron a circular libremente y a adquirir valor" (2010, p.11). Además enfatiza que existiría una relación directa entre la posesión de qeros y aquillas y/o cocos de plata y los nuevos estatus femeninos que comenzaban a consolidarse: mujeres comerciantes, chicheras, incluso prestamistas. Ciertamente que sus ocupaciones daban cuenta de los profundos cambios que se estaban viviendo respecto de las inserciones y adaptaciones de mujeres indias en un distrito urbano como La Plata, pero también esta situación era extensible a Cusco, Arequipa y La Paz (Glave, 1989). Estas mujeres ocupaban un lugar en las jerarquías sociales urbanas, lo que también se expresaba en los bienes que tenían. La posesión de estos objetos permite reconocerlas como "personas 'influyentes', surgidas de los nuevos contextos coloniales que pudieran, o no, tener su origen en antiguos lazos de acatamiento y legitimidad comunitarios; en otros, probablemente [los objetos] fueron adquiridos como bienes demostrativos de riqueza y poder" (Martínez et al., 2016, p. 37).

Mujeres que además migraban desde espacios rurales, fenómeno que se intensificó en la segunda mitad del siglo XVII (Glave, 1989). Sin embargo, ellas seguían manteniendo sus vínculos o relaciones con esos espacios rurales cercanos a la ciudad, como los pueblos de Arabate y de Guata. Cabe la pregunta acerca de cómo esos qeros y aquillas llegaron a formar parte de sus efectos personales. ¿Por compra?, ¿por herencia?, ¿por sus lazos de parentesco con originarios de los pueblos de Arabate y Guata?

\section{Avanzando en las conclusiones para tejer hilos en el mapa (Figura $1^{53}$ )}

$\mathrm{Al}$ mirar el mapa, un primer hilo que se reconoce es que la antigua ciudad de Cusco emerge como un espacio de presencia significativa de objetos y oficios de indios. Carpinteros, olleros, pintores y plateros transitaban entre talleres de producción urbana, elaboraciones de objetos dirigidos a conventos y monasterios, pero también acordando contratos de trabajo o de obra con españoles. Los plateros tenían un espacio de producción fuertemente controlado por las ordenanzas del virrey Toledo. Algunos eran originarios de las yungas, otros procedían de Pampamarca, Colquepata y de Paucarpata. Sus oficios mantenían ciertas continuidades con usanzas antiguas: algunos de ellos estaban unidos por lazos de parentesco, siendo sus oficios heredados de padres a hijos.

Es en la ciudad de Cusco donde con fuerza se observa la presencia de aquillas y/o cocos de plata, mates, qeros pintados, qeros de chonta, qeros de ńaccha, qeros grandes y pequeños, o simplemente vasos de palo o madera para beber. Esos objetos de indios estaban en manos de nativos, eran parte de su legendario $o$ inventario familiar, heredados entre parientes, entregados de padres a hijos y/o sobrinos; o de madres a hijas, mecanismos de herencia que permitían conservarlos al interior de las familias. Eran objetos en que se recordaba que "yo beuia" y "mando que lo goçe mi cuñado/ diego tanpu orcuuaranca" ${ }^{54} \mathrm{En}$ consecuencia, eran objetos activos, vivos en su uso y memoria.

53 El mapa que forma parte de este apartado fue construido para pensar aquillas, qeros y matis no solo desde el sur andino colonial, sino que también integrando los Andes Centrales, como las provincias de Guánuco, Guamanga y Huarochirí, a fin de ampliar la historicidad de la presencia de estos objetos de indios. Este mapa contiene tres niveles de información. Por una parte, objetos y materias primas entregados en tiempos del Tawantinsuyu. Por otra, objetos entregados por tasa en tiempos hispanos. Y por último, materias primas entregadas por tasa en tiempos hispanos. Junto a estas informaciones, se incorporaron datos que dan cuenta de oficios de indios u oficios a su usanza.

54 ARC, Pedro de la Carrera Ron Protocolo N ${ }^{\circ}$ 5, 15861596, f. 694r. Paleografía de Eliana López. 


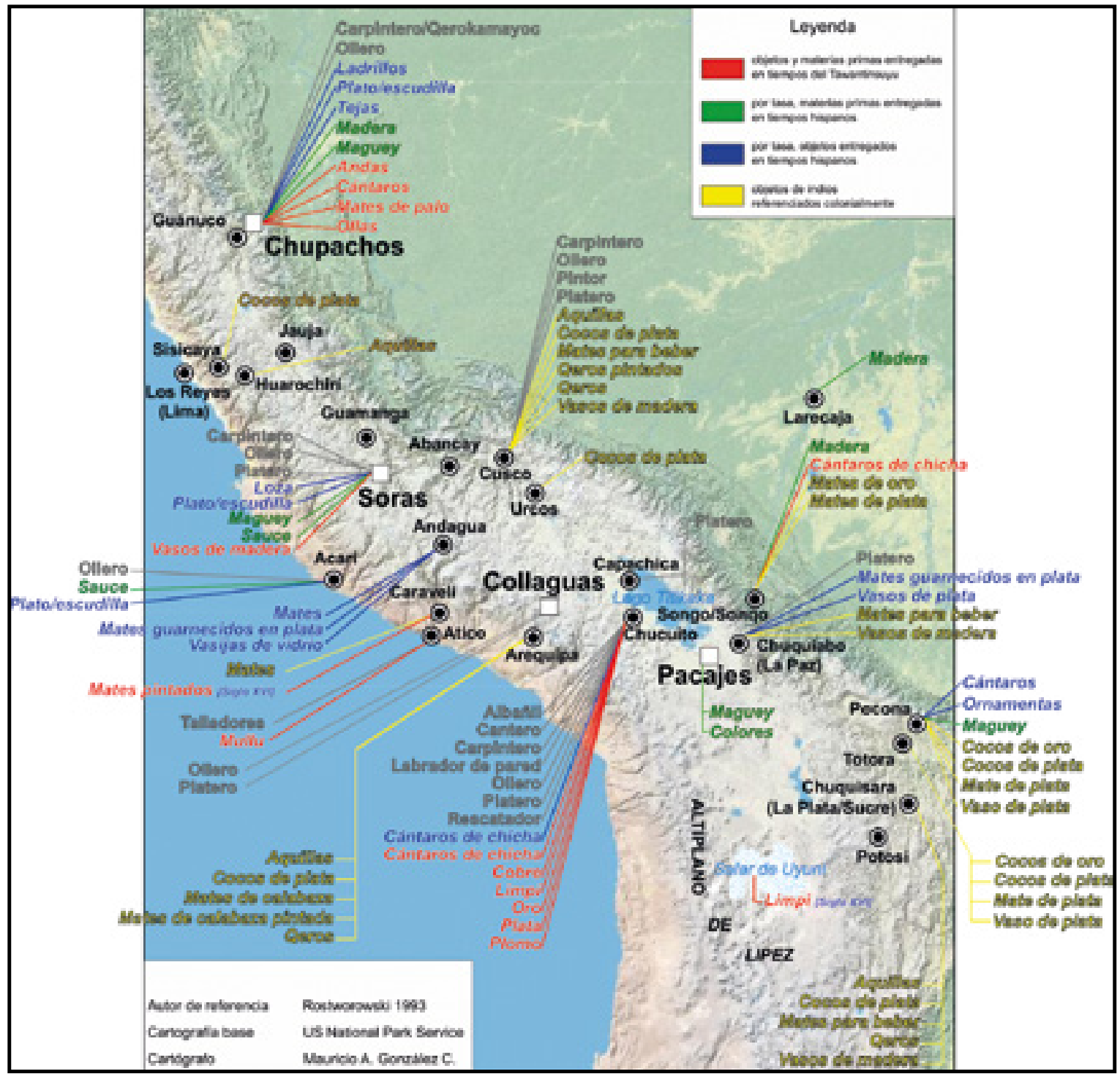

Figura 1. Circulaciones de materias primas, objetos y oficios de indios.

Un segundo hilo que se traza al mirar el mapa, es que la presencia de objetos de indios es significativa en Cusco, Arequipa, La Paz y La Plata, porque ellas eran "sedes de múltiples funciones administrativas, religiosas, militares, culturales y, por supuesto, económicas" (Glave, 1989, p. 29). Están al interior de las unidades familiares, traza que es posible distinguir sobre todo en los testamentos de indios revisados correspondientes al distrito urbano de Cusco y Arequipa. Están en manos de hombres y mujeres indígenas, y experimentan destinos imprevisibles cuando son rematados en almoneda pública y sus nuevos dueños no necesariamente son gentes indias.

Un tercer hilo significativo lo constituye la presencia de mates, fundamentalmente pintados en el ámbito de la costa-valle-sur del Perú, en las áreas de Atico, Caravelí y Chuquibamba, producción controlada por los hispanos y dirigida al consumo/demanda de gentes indias. Los matis/qeros pintados circulaban junto al maguey, platos y escudillas de madera, recursos y productos que tenían que entregar los indios por tasa 
(Rostworowski, 2005 [1993], pp. 262-302). También se reconoce la existencia de ayllus de plateros en el valle del Colca (Arequipa), en el repartimiento de Yanque Collaguas, parcialidad de Anansaya. En la visita de 1616 se detecta la existencia de un "aillo de los indios plateros reduçidos en este pueblo de Maca, de la parcialidad de Hanansaia, de que es principal Pedro Iba Raca" (Robinson, 2006, p. 374, f., 326v). La visita no permite detectar las características del oficio de plateros. El ayllu estaba formado por 22 casas y habitado por 146 personas (Robinson, 2006, p 385, f. 338r). En el ámbito de la parcialidad de Urinsaya, igualmente en el contexto del repartimiento Yanque Collaguas, se detecta un ayllu de indígenas plateros, en el pueblo de Achoma, conformado por el ayllo Collana Pataca, "yndios plateros de este mismo aillo" (Robinson, 2006, p. 322, f. 385 v.).

Un cuarto hilo de este tejido se reconoce para la cuenca circumtitikaka, particularmente el área de Chucuito y Capachica, que destaca como un nodo de circulación y producción de materias primas, productos, mercancías y oficios, integrando espacios relativamente distantes: Moquegua, Arequipa, La Paz, Potosí y Cusco, entre otros. Se observa la producción de cántaros de chicha, y la presencia de albañiles, plateros, olleros, carpinteros y rescatadores. Hay una importante circulación de maderas y ornamentos para la construcción de iglesias y capillas en el área, a cargo de las autoridades nativas, con ayuda de mano de obra indígena. Y todo ello reglamentado por tasa.

Es en el distrito urbano de La Paz donde se levanta un quinto hilo, con vasos y mates de madera que forman parte de las borracheras al interior de las casas de la indianidad. Se relataba que en ellas se bebía y bailaba al son de tamboriles y utilizando vasos de madera en patrón de a pares. Llama la atención la ausencia de documentación en los siglos XVII y XVIII sobre la continuidad de la presencia de vasos de madera, intensificándose aquella de mates guarnecidos en plata y tachos de plata, además de una serie de objetos, como las tallacllas, asociados al acto de beber mate. En la zona de yungas de La Paz, en el área del repartimiento de Songo/Sonqo, los hispanos controlaban, por tasa, la circulación de madera y la producción de cantaros de chicha. Se observa la permanencia de cocos de plata entre autoridades nativas, los que claramente tenían un uso ritual (Murra (Comp.), 1991).

Para el Altiplano central de Bolivia, en el área de Pacajes, se observa un sexto hilo conformado por la circulación de colores. También para el Altiplano central de Bolivia, en el pueblo de Caquiaviri [Cacayacure], Pacajes, se verifica, por tasa, la circulación de maguey.

Para la zona sureste de Cochabamba, en las áreas de Pocona y Totora, se aprecia, por tasa, otro hilo, conformado por la circulación de maguey y la existencia de cocos de plata en manos de autoridades nativas. Mercedes del Río (2010) propone que en los valles de Pocona, Totora y Tapacari, para tiempos coloniales tempranos, los mallku conservaban una serie de objetos de oro y plata, los que no solo correspondían a objetos de prestigio y autoridad, sino que también tenían una historicidad que se anclaba en tiempos del Tawantinsuyu, en la época en que esos valles estaban vinculados al imperio, no solo por las necesidades de su defensa como frontera, sino también por sus actividades agrícolas, especialmente aquellas relacionadas con los cocales. Señala la autora que "don Pedro Chirima y don Juan Jarajuri de los Quta, el Qulla don Pedro Arapa (de Azangaro') y el cacique de los Charka de Totora don Pedro Xauxa tenían un significativo ajuar" (Del Río, 2010 , p. 207). En relación a los objetos de plata, se menciona que eran los plateros indios de Sipesipe $^{55}$ los que en la década de 1570 aún "proveían de objetos de oro o plata a los caciques locales o por lo menos a los de Pocona y de Tapacari" (Del Río, 2010, p. 208). Entre los objetos destacan los que conservaba Pedro Arapa: una bacinilla de plata o "mate para beber", seis pares de cocos de plata siendo singulares: "dos con pajarillas de oro y otros 2 con dos cintas con cintas de oro" (Del Río, 2010, p. 215). A su vez, Juan Xaraxuri o Jarajuri tenía cocos de oro y tres pares de cocos de plata. Y Pedro Chirima tenía cuatro pares de cocos de plata (Del Río, 2010, p. 214).

55 "Se trata de mitmaqkuna Icayungas" (Del Río, 2010, p. 220). 
Para la zona de Chuquisaca, área de Churumatas y Charcas, se aprecia otro hilo, a partir de la circulación, por tasa, de ornamentos religiosos y cántaros. Es significativa la presencia de mates pintados, no solo circulando entre indígenas, sino que formando parte de tiendas de mercaderes. También resulta interesante la importante presencia, entre mujeres indígenas, de qeros, aquillas y/o cocos de plata.

Y, finalmente en el Altiplano sur de Bolivia, en el área de Lipes, se observa la circulación de limpi o llimpi.

Aquillas, qeros y matis se conservan en manos de kuracas coloniales y familias, ¿y qué ocurre con los usos de los objetos al interior de las parcialidades? No se cuenta con datos que permitan alumbrar la vida de las aquillas en manos de los señores naturales. Información existente para el ámbito de Sisicaya (ver Figura 1) permite reconocer que en 1588 el kuraca de San Francisco de Sisicaya, Diego Chauca Guaman, tenía "tres pares de cocos de plata" (Salomon, Feltham y Grosboll, 2009, p. 125). El kuraca fue acusado como indio idolatra y hechicero, lo que hace pensar que le fueron requisados (Brosseder, 2014, p. 119).

Otro dato que permitiría pensar en sus usos y circulaciones es el que se refiere para la provincia de Huarochiri. El corregidor Diego Dávila Briceño en 1586 recibió información sobre que:

[...] habrá cuatro años, poco mas o menos, que yo, el dicho corregidor, castigue algunos caciques, siendo corregidor de la parte superior desta provincia que llaman Anan Yauyos, y les quite cuatrocientas cabesas de ganado desta tierra con catorce vasos de plata, con que hacían sus sacrificios cada luna, que se vendió y se metió en la caja real (Davila Brizeño 1586 en Jiménez de la Espada, 1965. Tomo I, p. 161, negritas nuestras).

¿Habrán sido fundidas? ¿Habrán sido rematadas públicamente?

Aún queda mucho por profundizar sobre contextos de producción y circulación colonial de aquillas, qeros y matis, tanto en espacios urbanos como rurales.
Resulta también importante indagar en sus modos de inserción en los mercados regionales. Estas notas de investigación arrojan luces, pero también sombras, y plantean preguntas abiertas, como por ejemplo si acaso la permanencia de estos objetos de indios permitiría pensar en la pervivencia de modos de producción andinos en comunidades especializadas como los pueblos de mates y los ayllu de plateros. Y si los pueblos de queros coexistirían junto a modos de producción europea. El vocablo Quero está presente en distintos pueblos. Por ejemplo, y aunque distante del sur andino, se observa en la Figura 1, para la provincia de Guánuco, que en el territorio de los señores Chupachos había pueblos Queros habitados por "queroscamayos", qerokamayoc y/o camayoc, es decir, especialistas o expertos/diestros en el oficio de carpinteros (Archivo General de Indias, Sevilla, Justicia, Legajo 397, en Helmer, 1955 [1549], p. 28, f. 153v, negritas nuestras). A su vez, en tiempos del Inca "llevaban mates de palo que los ponían en Guanuco el Viejo" (Visita de la provincia de León de Huánuco, en Murra (Comp.), 1967 [1562], p. 26, f. 10r, negritas nuestras). En la provincia de Guamanga se señala que existía un pueblo llamado Santiago de Queros; "se llamó así, porque queros en lengua de los indios quiere decir maderos, y porque en este pueblo hay una arboleda de alisos, por esto le nombraron así, y no dan los indios otra razón" (Monzón 1586, en Jiménez de la Espada, 1965. Tomo I, p. 230). También existía otro pueblo, Queropampa. ¿Se estaría haciendo alusión a una pampa de madera, es decir, atendiendo a la existencia de materia prima, los árboles, y por tanto, madera, y posiblemente de ahí, la especialización de algunas comunidades, por ejemplo, de carpinteros? Luego quero refiere a "Vaso de madera" y Qqueru a "Madera gruessa, o delgada todo lo ques materia de carpintero que se labra" (González Holguín, 1989 [1608], pp. 305 y 306, respectivamente).

Para finalizar, se reconoce que aquillas, qeros y matis circulaban en ámbitos individuales, familiares y comunitarios y se seguían produciendo para gentes indias, en un mundo y tiempos de cambios y transformaciones, pero también de permanencias y pervivencias. 


\section{Agradecimientos}

Este trabajo es parte de los resultados obtenidos en el proyecto FONDECYT 1130431, Sistemas andinos de registro y de comunicación y semiosis andina colonial.

Mis reconocimientos a los/las ayudantes del área de etnohistoria del proyecto. A la primera banda formada por Eliana López y Esteban Miranda se sumó Álvaro Durán y, posteriormente, Natalia Guíńez, Vicente González y Tania Zúñiga. Gracias por sus tiempos, trabajos y dedicación al proyecto. A mis colegas del proyecto FONDECYT 1130431 y a las observaciones atentas de José Luis Martínez Cereceda, investigador responsable del mismo. Agradezco también las observaciones de los evaluadores, los focos sugeridos, las lecturas propuestas, las críticas formales y las necesarias reingenierías.

\section{Referencias citadas}

Academia Mayor de la Lengua Quechua (2005). Diccionario Quechua- Español-Quechua. Qheswa-EspañolQheswa. Simi Taque. Cusco: Gobierno Regional del Cusco. Recuperado de http://ec.unsaac.edu.pe/Usuario/temporal/DICIONARIO/Diccionario\%20Quechua\%20Peru.pdf

Assadourian, C. S. (1982). El sistema de la economía colonial. Mercado interno, regiones y espacio económico. Lima: Instituto de Estudios Peruanos.

Bertonio, L. (1612). Vocabulario de la lengua aymara. Juli: Impreso en la Casa de la Compañía de Jesús de Juli en la provincia de Chucuito por Francisco del Canto.

Brosseder, C. (2014). The Power of Huacas. Change and Resistance in the Andean World of Colonial Peru. Austin: University of Texas Press.

Carcedo, P., Vetter, L. y Diez Canseco, M. (2004). Los vasos-efigie antropomorfos: Un ejemplo de la orfebrería de la costa central durante el Período Intermedio Tardío y el Horizonte Tardío. Boletín de Arqueología PUCP, 8, 151-189.

Cummins, T. (2002). Toast with the Inca. Andean Abstraction and Colonial Images on Quero Vessels. Ann Arbor: University of Michigan Press.
Cummins, T. (2004). Brindis con el Inca. La abstracción andina y las imágenes coloniales de los queros. Lima: Universidad Nacional Mayor de San Marcos - Universidad Mayor de San Andrés - Embajada de los Estados Unidos.

Cummins, T. (2005). La fábula y el retrato: imágenes tempranas del inca. En Los incas, reyes del Perú (pp. 1-41). Lima: Banco de Crédito.

Diez de San Miguel, G. (1964) [1567]. Visita hecha a la provincia de Chucuito por Garci Diez de San Miguel en el año 1567. Lima: Ediciones de la Casa de la Cultura del Perú.

Egido, C. (2013). Indigenismos en la vida cotidiana de la América Colonial (Siglos XVII-XVIII). Signo y seña, 23, 23-38.

Escobari, L. (2004.) Producción y comercio en la historia de Bolivia colonial. Siglos XVI-XVIII. La Paz: Plural editores.

Espinoza, W. (1987). Artesanos, transacciones, monedas y formas de pago en el mundo andino. Siglos XVy XVI. Tomo I. Lima: Banco Central de Reserva del Perú.

Esquivel y Navia, D. de (1980) [1749]). Noticias cronológicas de la gran ciudad del Cuzco. Tomo 1 y 2. Edición, prólogo y notas de Félix Denegri Luna con la colaboración de Horacio Villanueva Urteaga y César Gutiérrez Muńoz. Lima: Fundación Augusto B. Wise, Banco Wise LTDO.

Flores, J., Kuon-Arce, E. y Samanez, R. (1997).Vasos de madera, Región del Lago Titicaca. Arkinka, 25, 102111.

Galdames, L. y Marsilli, M. (Comps.) (2012). Culto a los ancestros, hechiceros y resistencia colonial: El caso de Gregorio Taco, Arequipa, 1750. Arica: Ediciones Universidad de Tarapacá - Ediciones Cinosargo - John Carroll University.

Galdós, G. (1975-1976). Visita a Atico y Caravelí (1549). Revista General de Archivo de la Nación, 4-5, 55-80.

Garcilaso de la Vega, I (1991) [1609]. Comentarios reales de los Incas. Araníbar, C. (Ed.). Lima: Fondo de Cultura Económica.

Gil García, F. (2009). Lipes en los siglos XIV-XVII. Construcción de una región geohistórica identitaria en el altiplano surandino y clasificaciones coloniales. Memoria 
para optar al grado de doctor. Facultad de Geografía e Historia, Departamento de Historia de América II (Antropología de América), Universidad Complutense de Madrid, Madrid.

Gisbert, T. (1999). El paraíso de los pájaros parlantes. La imagen del otro en la cultura andina. La Paz: Plural - Universidad de Nuestra Señora de La Paz.

Glave, L. M. (1989). Trajinantes. Caminos indigenas en la sociedad colonial. Siglos XVI y XVII. Lima: Instituto de Apoyo Agrario.

González, L. (1982). El libro del cabildo de la ciudad del Cuzco. BIRA, 11, 173-360.

González Holguín, D. (1989) [1608]. Vocabulario de la Lengua General de todo el Perú llamada Lengua Qquichua $o$ del Inca. Lima: Universidad Nacional Mayor de San Marcos.

Guaman Poma de Ayala, F. (1980 [1615-1616]). El primer nueva corónica y buen gobierno. Murra, J. y Adorno, R. (Eds.). México D.F.: Siglo XXI.

Gutiérrez, R. (1979). Notas sobre la organización artesanal en el Cusco durante la colonia. Histórica, III(XXX), 1-15.

Gutiérrez, R., Azevedo, P., Viñuales, G. y Vallin, R. (1981). La casa cusqueña. Resistencia: Universidad Nacional del Nordeste.

Helmer, M. (1955). "La visitación de los Yndios Chupachos": Inka et encomendero 1549. Travaux de L'Institut Français D'Études Andines, 5, 3-50.

Jiménez de la Espada, M. (1965). Relaciones Geográficas de Indias. Perú. Tomos I y II. Madrid: Biblioteca de Autores Españoles, Ediciones Atlas.

Kuon-Arce, E. (2011). Artes utilitarias y Barroco. Notas sobre la cerámica vidriada en el Surandino. En Barroco y fuentes de la diversidad cultural. Memoria del II Encuentro Internacional, Pamplona, Fundación Visión Cultural - Servicio de Publicaciones de la Universidad de Navarra (pp. 123-136). Edición digital a partir de La Paz, Viceministerio de Cultura de Bolivia/ Unión Latina, 2004. Recuperado de http://www.unav.edu/publicacion/ encuentros-barroco-bolivia/segundo-encuentro
Lizárraga, R. de (2002 [1594-1607]). Descripción del Perú, Tucumán, Río de La Plata y Chile. Ballesteros, I. (Ed.). Madrid: Dastin, S.L.

Málaga, A. (1975). Los corregimientos de Arequipa. Siglo XVI. Historia, 1, 47-85.

Marsilli, M. (2014). Hábitos perniciosos: Religión Andina Colonial en la Diócesis de Arequipa (Siglos XVI al XVIII). Santiago: Centro de Investigaciones Diego Barros Arana, Dibam.

Martínez, D. (2015). Teatralidades de calle en el Cuzco colonial. Atenea, 511, 125-145. doi:10.4067/S071804622015000100007

Martínez, G. (1981). Espacio Lupaqa: algunas hipótesis de trabajo. Etnohistoria y Antropología Andina. Segunda Jornada del Museo Nacional de Historia Lima, 263-280.

Martínez, G. (1989). Espacio y pensamiento I. Andes meridionales. La Paz: Hisbol.

Martínez, J. L. (1995). Papeles distantes, palabras quebradas. Las informaciones sobre lipes en el siglo XVI. En Espacio, etnias, fronteras. Atenuaciones politicas en el sur del Tawantinsuyu, siglos XV-XVIII (pp. 285-317). Sucre: Ediciones ASUR N ${ }^{\circ} 4$.

Martínez, J. L. (2011). Gente de la tierra de guerra. Los lipes en las tradiciones andinas y el imaginario colonial. Santiago, Lima: Pontificia Universidad Católica del Perú Centro de Investigaciones Diego Barros Arana, Dibam.

Martínez, J. L. (2012). El virrey Toledo y el control de las voces andino coloniales. Colonial Latin American Review, 21(2), 175-208. doi:10.1080/10609164.2012.695574

Martínez, J. L. y Martínez, P. (2013). Narraciones andinas coloniales, oralidad y visualidad en los Andes. Journal de la Société des Américanistes, 99-2, 41-81. doi:10.4000/ jsa. 12858

Martínez, J. L., Díaz, C., Tocornal, C. y Arévalo, V. (2014). Comparando las crónicas y los textos visuales andinos, elementos para un análisis. Chungara. Revista de Antropología Chilena, 46(1), 91-113. doi: 10.4067/S071773562014000100006

Martínez, J. L., Díaz, C., Tocornal, C., Acuña, G. y Narbona, L.M. (2016). Qeros y discursos visuales en la cons- 
trucción de la nueva sociedad colonial andina. Anuario de Estudios Americanos, 73(I), 15-43. doi:10.3989/aeamer.2016.1.01

Masuda, S. (1982). Dinamismo Inter-regional en los Andes centrales. SENRI Ethnological Studies, 10, 93-106.

Money, M. (2004). Oro y plata en Los Andes. Significado en los diccionarios de aymara y quechua. La Paz: Colegio Nacional de Historiadores, Producciones Cima.

Murra, J. (1964). Una apreciación etnológica de la visita. En Visita hecha a la provincia de Chucuito por Garci Diez de San Miguel en el año 1567 (pp. 419-442). Lima: Ediciones de la Casa de la Cultura del Perú.

Murra, J. (Ed. y Comp.). (1967). Visita de la provincia de León de Huánuco en 1562. Iñigo Ortiz de Zuñiga, visitador. Tomo I. Huánuco: Universidad Nacional Hermilio Valdizan.

Murra, J. (Ed. y Comp.). (1991). Visita de los valles de Sonqo en los yunka de coca de la Paz [1568-1570]. Madrid: Instituto de Investigaciones Andinas, Instituto de Cooperación Iberoamericana, Sociedad Estatal Quinto Centenario e Instituto de Estudios Fiscales.

Murra, J. (2002). El mundo andino. Población, medio ambiente y economía. Serie Historia Andina, 24. Lima: Pontificia Universidad Católica del Perú, Instituto de Estudios Peruanos.

Ocaña, D. de, fray (1599-1605). Relación del viaje de Fray Diego de Ocaña por el Nuevo Mundo (1599-1605). Oviedo: Repositorio institucional Universidad de Oviedo. Recuperado de http://digibuo.uniovi.es/dspace/handle/10651/27859

Odone, C. y Durán, A. (2017). Circulaciones incesantes de objetos indígenas andino-coloniales; qeros, mates y cocos de plata de Francisca Palla (Arequipa, 1564). Meridional. Revista Chilena de Estudios Latinoamericanos, 8, 45-72. doi:10.5354/0719-4862.2017.45394

Pease, F. (1982). Relaciones entre los Grupos étnicos de la Sierra Sur y la Costa: Continuidades y Cambios. SENRI Ethnological Studies, 10, 107-122.

Pease, F. (1992). Perú, Hombre e Historia entre el siglo XVI y el XVIII, vol. II. Lima: Edubanco.
Presta, A. M. (2010). Desde la Plaza a los Barrios. Pinceladas étnicas tras las casas y las cosas. Españoles e indios en la ciudad de La Plata, Charcas 1540-162. Nuevo Mundo Mundos Nuevos [En ligne], Débats, mis en ligne le 10 janvier 2010, consulté le 27 octobre 2015. Recuperado de http://nuevomundo.revues.org/58926. doi: 10.4000/ nuevomundo.58926

Quiroz, F. (2008). Artesanos y manufactureros en Lima colonial. Lima: Instituto de Estudios Peruanos.

Ramos, G. (2005). Los símbolos de poder inca durante el virreinato. En Los incas, reyes del Perú (pp. 43-65). Lima: Banco de Crédito.

Relaciones de los virreyes y audiencias que han gobernado el Perú (1867). Memorial y Ordenanzas de D. Francisco de Toledo 1569-1574. Tomo I. Lima: Imprenta del Estado.

Río, M. del (2010). Los tesoros de los Malku de Pocona y Totora en el siglo XVI. Chungara. Revista de Antropología Chilena, 42(1), 199-220. doi:10.4067/ S0717-73562010000100030

Robinson, D. J. (Comp.) (2006). Collaguas III Yanque Collaguas. Sociedad, economía y población, 1604-1617. Homenaje a Franklin Pease. Lima: Fondo Editorial de la Pontificia Universidad Católica del Perú y Syracuse University.

Rostworoswski, M. (1970). Mercaderes del valle de Chincha en la época prehispánica: Un documento y unos comentarios. Revista Española de Antropología Americana, 5, 135-177.

Rostworoswski, M. (2005 [1993]). Ensayos de historia andina I. Elites, etnias, recursos. Lima: Instituto de Estudios Peruanos.

Rowe, J. (1990). El plano más antiguo del Cuzco. Dos parroquias de la ciudad vistas en 1643. Histórica, XIV(2), $367-378$

Saignes, T. (1980). Una provincia andina a comienzos del siglo XVII: Pacajes según una Relación inédita. Separata de Historiografía y Bibliografía Americanistas, XXIV, 3-21.

Salomon, F., Feltham, J. y Grosboll, S. (2009). Revisita de Sisicaya, 1588: Huarochiri, veinte años antes de Dioses y Hombres. Lima: Pontificia Universidad Católica del Perú - Asociación Atocongo. 
Takahashi Martínez, Y. V. (2012). Gregorio Taco, cacique rebelde e idólatra (Andagua, 1748-1755). Tesis para obtener al grado de licenciada en Historia, Facultad de Letras y Ciencias Humanas, Pontificia Universidad Católica del Perú, Lima.

Valenzuela. J. (2010). Devociones de inmigrantes. Indígenas andinos y plurietnicidad urbana en la conformación de cofradías coloniales (Santiago de Chile, siglo XVII). Historia, 43(I), 203-244. doi:10.4067/S071771942010000100006

Vásquez de Espinosa, A. (1948 [1628-1629]). Compendio y descripción de las Indias Occidentales. Washington D.C.: Smithsonian Institution.

Vetter, L. (2008). Plateros indigenas en el Virreinato del Perú: siglo XVI y XVII. Lima: Universidad Nacional Mayor de San Marcos.

Vetter, L. (2016a). Una mirada a la tecnología orfebre andina desde una perspectiva interdisciplinaria. Reunión Anual de Etnología 30. Rebelión de los objetos. Minería y Metales, 31-58.

Vetter, L. (2016b). Plateros y saberes andinos: El arte orfebre en los siglos XVI y XVII. Cusco: Centro de Estudios Regionales Andinos Bartolomé de Las Casas.

Zasada, M. (1985). Producción artesanal en el Tawantinsuyu. Estudios Latinoamericanos, 10, 67-94.

Ziółkowski, M. (1979). Acerca de algunas funciones de los keros y las akillas en el Tawantinsuyu incaico y en el Perú colonial. Estudios Latinoamericanos, 5, 11-24.

\section{Fuentes inéditas}

\section{Archivo Arzobispal de Arequipa (AAA):}

- Vicarías, Condesuyos, Andaguas 2, Testamento de Pedro de Portugal de Torres, 1698.

\section{Archivo Regional de Arequipa (ARA):}

- Antonio de Herrera Protocolo N ${ }^{\circ}$ 49, testamento de Ana Choncaya, 1586, f. 290r-291r. Testamento de Barbola Poco, 1588, f. 221r-221v.
- Diego Navarro Protocolo $N^{\circ} 81$, testamento de Juan Guacondori, 1586, f. 162v-167r.

- Juan de Torres Protocolo No 84, testamento de Francisca Palla, 1564, f. 1r-3v.

- Sebastián Mariño Protocolo N 187 , testamento de Francisca Tia, 1611, f. 164v-166v.

- García Muñoz Madueño Protocolo N²01, testamento de Ana Chuqirima, 1606, f. 100r-103r. Testamento de Lorenzo Tupache, 1607, f. 100r-104r.

\section{Archivo La Paz (ALP):}

- Expedientes coloniales Caja 129 E27, testamento de Theresa Trujillo, 1799, 1r-5v.

- Expedientes Coloniales Caja 122 E39, testamento de don Gregorio Barros, 1795, 1r-3v.

- Registro de escrituras Testamentos Caja 61 Legajo 93, testamento de Ana Carrasco, 1704, 522v-523v.

- Registro de escrituras Testamentos Caja 63 Legajo 95, testamento de Juan/Julian de Criales, 1706, 367r-370v.

- Registro de escrituras Testamentos Caja 63 Legajo 95, testamento de Isabel Mallqui, 1707, 704r-705v.

- Registro de escrituras Testamentos Caja 64 Legajo 96, testamento de Marcos de Trujillo, 1711, sin número de fojas.

- Registro de escrituras Testamentos Caja 64 Legajo 97 (5), testamento de Ana Coronel, 1712, 305r-307v.

- Registro de escrituras Testamentos Caja 70 Legajo 107, testamento de Ynes de Criales, 1723, 61r-62v.

- Registro de escrituras Testamentos Caja 71 Legajo 111 (2), testamento de Ignacio Larreta Beramendi, 1729, $218 \mathrm{r}-235 \mathrm{r}$.

\section{Archivo y Bibliotecas Nacionales de Bolivia (ABNB):}

- Escribanos Públicos de La Plata EP, 117, Inventario de los bienes de Gonzalo de Figueredo, 1619, 51r-77r. 


\section{Archivo Regional de Cusco (ARC):}

- Pedro de la Carrera Ron Protocolo No 5, testamento de Alonso Hanco, 1586, 692r-697r. Testamento de Anjelina Tambo, 1586, 696v-698v. Testamento de Ana Cochauto, 1589, f. 270r-271r. Testamento de Pedro Cancho, 1589, f. 860r-862v. Testamento de Juan Gualpa Succo Ynga, 1590, 873v-877r. Testamento de Maria Chuqye Samay, $1590,40 \mathrm{v}-41 \mathrm{v}$.

- Antonio de Salas Protocolo $N^{\circ} 18$, testamento de Luisa Tari, 1597, 727r-729v.

- Antonio Sánchez Protocolo $N^{\circ} 22$, testamento de Catalina Poco, 1571, 63r-63v.

- Corregimiento Legajo 7 Cuaderno 12, Autos de información que presentan Diego Massi, Francisco Chuqui y Diego Guamani naturales del pueblo de Pampamarca de la encomienda de Francisco de Loaysa indicando que ellos son maestros plateros y como tales piden ser reservados de mita y servicios personales, Cusco, 1624, 1r-6v.

- Revista del Archivo Histórico del Cuzco, 1952, núm. 3. 